\title{
The Frequency of Revertants in mdx Mouse Genetic Models for Duchenne Muscular Dystrophy
}

\author{
ISTVAN DANKO, VERNE CHAPMAN, AND JON A. WOLFF \\ Departments of Pediatrics and Medical Genetics, Waisman Center, University of Wisconsin, \\ Madison, Wisconsin 53705 [I.D., J.A.W.]; and Department of Molecular and Cellular Biology, Roswell Park \\ Memorial Institute, Buffalo, New York 14263 [V.C.]
}

\begin{abstract}
The mdx mouse has been used for the development of cellular and gene therapies for Duchenne muscular dystrophy. The relatively frequent occurrence of dystrophin-positive muscle cells called revertants has hampered these efforts by interfering with data interpretation. The $\mathrm{mdx} 4^{\mathrm{cv}}$ and $\mathrm{mdx} 5^{\mathrm{cv}}$ dystrophin mouse mutants have approximately 10 -fold fewer revertants than the $\mathrm{mdx}$ mutant at both 2 and 6 mo. The $\operatorname{mdx} 3^{\text {cv }}$ dystrophin mouse mutant may be a useful model for some types of human dystrophin deficiencies in which the levels of dystrophin are low but not completely absent. (Pediatr Res 32: 128131, 1992)
\end{abstract}

Abbreviations

DMD, Duchenne muscular dystrophy

The mdx mouse containing a nonsense point mutation in the dystrophin gene is a genetic model for human DMD (1). The mouse has increased serum creatinine phosphate kinase levels and muscle pathology that includes necrosis, cellular infiltration, wide range of fiber size, and a large number of centrally nucleated fibers. In contrast to DMD, fibrosis and fatty deposits are not typical for mdx skeletal muscle. Nonetheless, the mdx mice have been helpful for increasing our understanding of DMD by elucidating the role of the dystrophin-associated glycoproteins (2) and the role of elevated myofiber calcium in its pathogenesis (35). An understanding of why the mdx mouse is different from human DMD may prove critical to the development of a successful therapy (6). A recent report indicates that mdx diaphragmatic muscle has pathology similar to human muscle (7).

New mutant alleles of $\mathrm{mdx}$ were recovered from female progeny of ethylnitrosourea-treated male mice that are designated $\mathrm{mdx} 2^{\mathrm{cv}}, \mathrm{mdx} 3^{\mathrm{cv}}$, and $\mathrm{mdx} 4^{\mathrm{cv}}(8)$. More recently, we have established a fourth allele, $\mathrm{mdx} 5^{\mathrm{cv}}$. The location of these new mutations has been established relative to a restriction fragment length polymorphism in the central region of the gene, such that $\mathrm{mdx} 2^{\mathrm{cv}}$, $-3^{\mathrm{cv}}$, and $-4^{\mathrm{cv}}$ map to the $3^{\prime}$ region of dystrophin gene, whereas mdx $5^{\mathrm{cv}}$ maps to the $5^{\prime}$ region (Chapman VM, Miller DR, unpublished data). These new mdx mutants lacked dystrophin in skeletal muscle as assayed by immunofluroescence and immunoblots and had skeletal muscle pathology similar to the original mdx mice.

A small percentage of the skeletal and cardiac muscle cells in

Received for rapid publication February 27, 1992; accepted March 31, 1992.

Correspondence and reprint requests: Jon A. Wolff, M.D., Waisman Center,

1500 Highland Ave., University of Wisconsin-Madison, Madison, WI 53705.

Supported by the Muscular Dystrophy Association (USA) and the National Institutes of Health (HD00352). mdx mice and humans with DMD contain dystrophin immunoreactivity against the background of dystrophin-negative cells (9). The nature of the dystrophin-positive cells referred to as revertants has yet to be determined. Postulated mechanisms for the revertants include 1 ) genomic deletion of the exon containing the point mutation, 2) expression of a suppressor transfer RNA, and 3) expression of dystrophin-related protein. The ability of the revertants in the mdx mice to be stained with several different antibodies that recognized all of the dystrophin domains suggested that the revertants were expressing the $\mathrm{X}$ chromosomeencoded dystrophin protein. The expression of a dystrophinrelated protein was altered in $\mathrm{mdx}$ mice, but its pattern of expression was different from that of the revertants $(10,11)$.

The $\mathrm{mdx}$ mouse has played a critical role in the development of new cellular transplantation and gene therapies $(12,13)$. The number of dystrophin-positive muscle cells before and after the experimental maneuvers is useful for assessing the efficacy of these experimental therapies. The presence of the revertants complicates this assessment. This study found that the $\mathrm{mdx} 4^{\mathrm{cv}}$ and $\mathrm{mdx} 5^{\mathrm{cv}}$ mutants contained approximately 10 -fold fewer revertants than the mdx mutants.

\section{MATERIALS AND METHODS}

Mouse strains. $\mathrm{Mdx}$ mice (C57BL/10 $\mathrm{mdx} / \mathrm{mdx}$ ) and control BALB/c mice were obtained either from Jackson Laboratories (Bar Harbor, ME) or from V. Chapman's laboratory, which obtained the mdx mice directly from G. Bulfield's laboratory. The $\mathrm{mdx} 2^{\mathrm{cv}}, \mathrm{mdx} 3^{\mathrm{cv}}, \mathrm{mdx} 4^{\mathrm{cv}}$, and $\mathrm{md} \times 5^{\mathrm{cv}}$ mutants were initially bred to congenicity onto the C57BL/6Ros background for more than 10 generations (8) and were subsequently maintained in both the Buffalo and Madison laboratories.

Dystrophin assays. Immunoblots were performed as previously reported using the 6-10 antibody $(13,14)$. After staining for dystrophin, the blots were stained with india ink to determine the amount of myosin that was transferred in each lane. Immunofluorescence analysis was performed on $6-\mu \mathrm{m}$ frozen sections as previously reported (13) using 1-2a antibody directed against the amino terminus (15), affinity-purified $30-\mathrm{kd}$ antibody directed against the rod domain (16), 6-10 antibody directed against another part of the rod domain (13), and d10 antibody against the carboxyl terminal domain $(9,16,17)$. The appropriate biotinylated secondary antibodies (Amersham, Des Plaines, IL) were used with Texas red streptavidin. Muscle sections were stained with hematoxylin and eosin for routine histologic examination (18). Nuclei were localized by staining with propidium iodide.

Statistical analysis was performed using $t$ tests. 


\section{RESULTS}

Skeletal muscle. The quadriceps muscles of the mutants were analyzed by immunofluorescent staining for dystrophin. As previously reported (8), the vast majority of the skeletal myofibers on the cross-sections from the $\mathrm{mdx} 2, \mathrm{mdx} 5$, and $\mathrm{mdx} 4$ mutants lacked dystrophin immunoreactivity. Unexpected results in the mdx 3 mutant will be presented below. As in the mdx muscles, the skeletal muscles in the $\operatorname{mdx} 2, \operatorname{mdx} 5$, and $m d x 4$ mutants had a few revertant fibers with dystrophin immunoreactivity at the sarcolemma. The most sensitive antibody, the 6-10 antibody, was used to reduce the chance of missing revertants with low levels of dystrophin (14). A large muscle group such as the quadriceps was chosen because its high number of revertants would provide a critical assessment of the number of revertants in the animals (9). Four to six quadriceps muscles were analyzed for each mutant. The number of revertants was counted in 1020 sections of the middle part of the quadriceps, which contains approximately 4000 myofibers. The number of revertants among the different sections of the same muscle varied by less than $15 \%$.

Figure 1 compares the mean number of revertants per quadriceps cross-section in the $\mathrm{mdx}, \mathrm{mdx} 2, \mathrm{mdx} 4$, and $\mathrm{mdx} 5$ mutants at 2 and $6 \mathrm{mo}$. At 2 and $6 \mathrm{mo}$, both the $\mathrm{mdx} 4$ and mdx 5 mutants had significantly fewer revertants than the $\mathrm{mdx}$ and $\mathrm{mdx} 2 \mathrm{mu}$ tants $(p<0.05)$. At 2 mo of age, the $\mathrm{mdx} 4$ and $\mathrm{mdx} 5$ mutants had approximately 5 - to 12 -fold fewer revertants than the $\mathrm{mdx}$ and $\mathrm{mdx} 2$ mutants. At 6 mo of age, the $\mathrm{mdx} 4$ and $\mathrm{mdx} 5$ mutants also had 8 - to 18 -fold fewer revertants than the $\mathrm{mdx}$ and $\mathrm{mdx} 2$ mutants. From 2 to $6 \mathrm{mo}$, the number of revertants significantly increased $(p<0.05)$ 6.2-fold in $\mathrm{mdx}$, 7.4-fold in $\mathrm{mdx} 2,4.0$-fold in mdx4, and 4.6-fold in mdx 5 mutants. In other muscles, such as the gastrocnemius, soleus, and diaphragm, the mdx4 and mdx 5 mutants also had less revertants than the mdx and mdx 2 mutants. Serial sections of the revertants in the $\mathrm{mdx}, \mathrm{mdx} 2$, $\operatorname{mdx} 4$, and $m d x 5$ mutants that were stained with the $6-10$ antibody were also stained to some degree with the $1-2 \mathrm{a}, 30-\mathrm{kd}$, and d 10 antibodies.

Sections of the mdx 3 quadriceps stained for dystrophin immunofluorescence with the 6-10 antibody revealed that all myofibers contained sarcolemmal, dystrophin immunofluorescence (Fig. 2B). However, the intensity of the dystrophin staining was less than that in normal mice (Fig. $2 A$ ), but greater than the levels in the nonrevertant fibers of the other mutants (Fig. 2C). An increased variability in the diameters of the myofibers from the $\mathrm{mdx} 3$ mice was also apparent. Other dystrophin antibodies (1-2a, $60-\mathrm{kd}$, and $\mathrm{d} 10$ ) yielded similar results for the $\mathrm{mdx} 3 \mathrm{mice}$.

In the $\mathrm{mdx}, \mathrm{mdx} 2, \mathrm{mdx} 4$, and $\mathrm{mdx} 5$ mutants, approximately $70-90 \%$ of the nuclei in both the dystrophin-positive and dystrophin-negative myofibers were centrally located at $6 \mathrm{mo}(n>500$

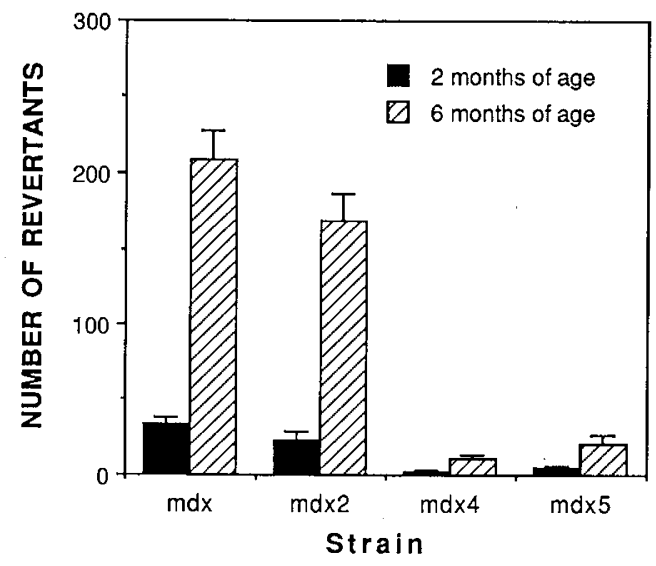

Fig. 1. The mean number of revertants in the mutants at 2 and 6 mo. The values represent the mean number of revertants in 10 to 20 sections of quadriceps muscles from four to six animals. Bars represent the SE.
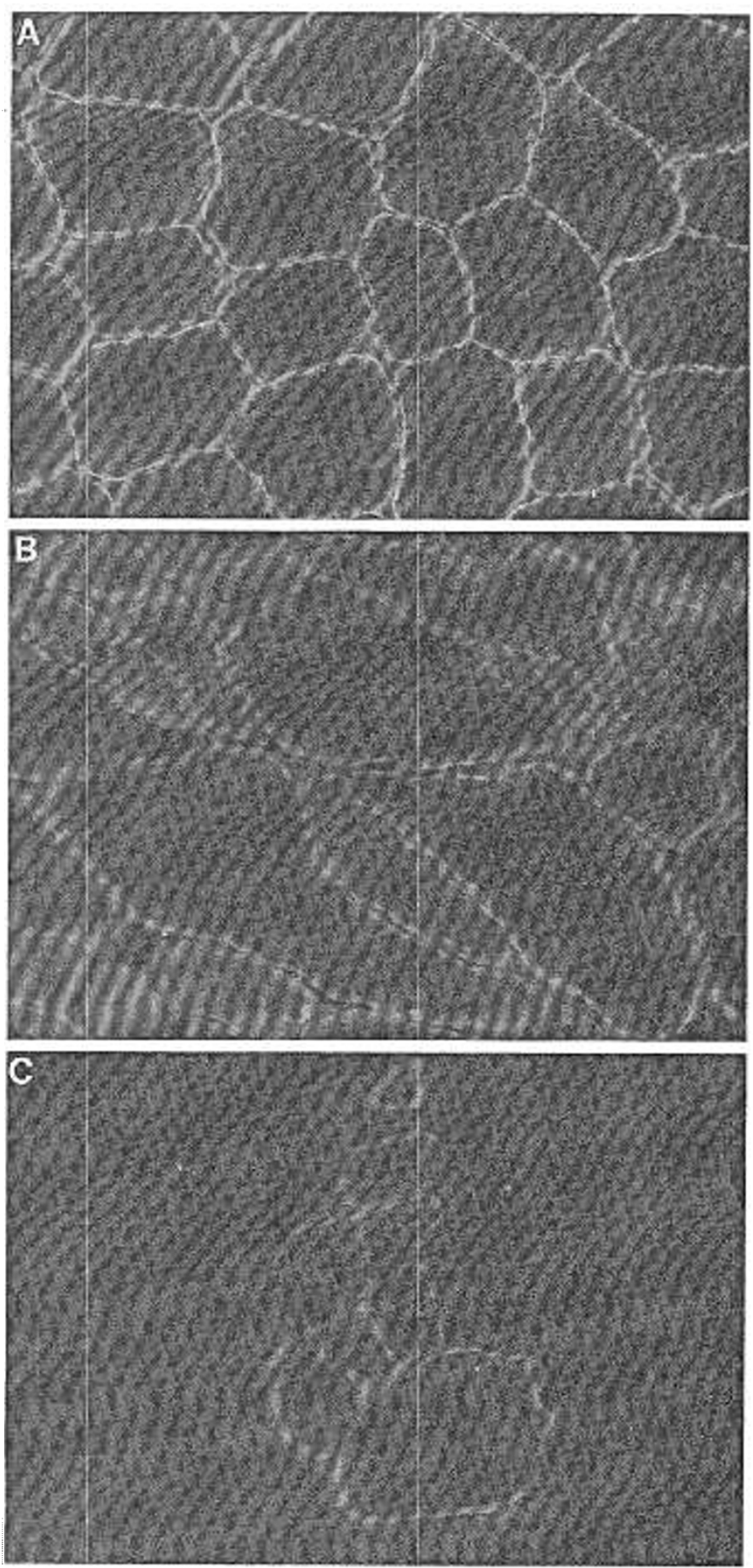

Fig. 2. Dystrophin immunofluorescence of 6-mo-old quadriceps muscles from a normal mouse $(A), \operatorname{mdx} 3$ mutant $(B)$, and $\mathrm{mdx} 4$ mutant $(C)$ showing a few revertants against a negative background. Magnification $\times 25$.

for each group). Greater than $70 \%$ of the $\mathrm{mdx} 3$ myofibers also contained central nuclei. Less than $1 \%$ of the myofibers from normal mice had central nuclei.

The diaphragms of $\mathrm{mdx}$ mice have substantially increased fibrosis, fatty infiltration, and necrosis with cellular infiltration than the skeletal muscles of the extremities (7). The diaphragms of all four mutants contained amounts of fibrosis, fatty infiltration, and necrosis similar to those in the mdx muscle. The pathologic findings were more extensive with increasing age in all the mutants. As previously reported (8), the pathologic findings of the skeletal and cardiac muscles in the four new $\mathrm{mdx}$ mutants were similar to those in the original $\mathrm{mdx}$ mice. 
Cardiac muscle. The number of revertants was evaluated in the myocardium of the $\mathrm{mdx}, \mathrm{mdx} 2, \mathrm{mdx} 4$, and $\mathrm{mdx} 5$ mutants (Table 1). Revertants were also present in cardiac tissue from 6mo-old mdx3 mutants because, unlike their skeletal muscle cells, all their cardiac cells did not have dystrophin immunofluorescence. At both 2 and $6 \mathrm{mo}$, the total number of revertants and clusters of revertants was greater in the $\operatorname{mdx} 2$ mutants than in the other mutants.

In the $\mathrm{mdx}, \mathrm{mdx} 2$, and $\mathrm{mdx} 4$ mutants, the number of revertants was similar at 2 and 6 mo. Revertants were not observed in the cardiac muscles from the mdx 5 and mdx 3 mutants at 2 mo, but were observed at 6 mo. Given the difficulty in accurately determining the number of cardiac revertants, more hearts from the mdx 3 and mdx 5 mutants must be analyzed to determine whether the numbers actually increase over time in these mutants.

Immunoblot analysis of skeletal and cardiac muscles. Immunoblots using the 6-10 antibody were performed on quadriceps and cardiac muscles from normal, BALB/c mice and the five mutants (Fig. 3). After staining for dystrophin, the blots were stained with india ink to determine the approximate amount of protein transferred. Some of the lanes contained a band above dystrophin that most likely represents the cross-reaction of the 6-10 antibody with nebulin (13). No band above dystrophin in size was observed in the heart extracts because cardiac tissue does not contain nebulin.

Dystrophin was not observed in skeletal muscles from the $\operatorname{mdx}, \operatorname{mdx} 2, \operatorname{mdx} 4$, or $\operatorname{mdx} 5$ mutants (Fig. $3 A$, lanes $2,3,6$, and $7)$, but low levels were observed as a faintly staining band in the mdx 3 mutants (Fig. 3A, lane 4). These results were observed on more than 20 immunoblots on muscles from eight animals for each of the different mutants. Given the reproducibility of finding faint dystrophin staining in the mdx 3 extracts and not in the other muscle extracts, it is unlikely that it was due to contamination.

Ten immunoblots were performed on extracts from five hearts

Table 1. Number of revertants in heart muscle of various mutants using 6-10 antibody

\begin{tabular}{cllllll}
\hline \multirow{2}{*}{ Mutant } & \multicolumn{3}{c}{$\begin{array}{c}\text { Number of revertants } \\
\text { at } 2 \text { mo* }^{*}\end{array}$} & \multicolumn{3}{c}{$\begin{array}{c}\text { Number of revertants } \\
\text { at } 6 \mathrm{mo}^{*}\end{array}$} \\
\hline mdx & 1,1 & 2 & 1,2 & 2 & 2 & 1 \\
& 1 & 2 & 1,1 & 0 & 1 & 1 \\
& $1,3,1,1$ & 1 & 1 & $1,2,2,2$ & 1,3 & 2,2 \\
& 1,1 & 2 & 1 & 2,3 & 1,1 & 2,1 \\
$\operatorname{mdx} 2$ & 1,2 & 1,1 & 1 & $1,1,1$ & $3,6,2,1,1$ & $1,1,1$ \\
& 1 & 0 & 1 & 1 & 1 & 1 \\
& $1,6,1$ & 5,1 & $1,1,4$ & 1,2 & $1,1,1$ & $2,1,1$ \\
& 2,1 & $1,1,1$ & $1,1,1$ & 2,2 & $2,1,1$ & $2,1,1$ \\
& $3,1,1$ & $1,1,3,5,3$ & $1,2,6,2,2$ & & & \\
& 8,1 & 6,2 & 2 & & & \\
$\operatorname{mdx} 3$ & 0 & 0 & 0 & 1 & 3 & 1 \\
& 0 & 0 & 0 & 0 & 0 & 0 \\
& 0 & 0 & 0 & 0 & 0 & 0 \\
& 0 & 0 & 0 & 4 & 1,1 & 3,1 \\
& 0 & 0 & 0 & & & \\
$\operatorname{mdx} 4$ & 0 & 0 & 0 & 1 & 1 & 1 \\
& 1 & 1 & 0 & 0 & 3 & 0 \\
& $1,2,2,1,4$ & $4,1,2,2$ & 2,2 & 1,1 & 2 & 1 \\
& 0 & 1,4 & 1 & 2,1 & 1 & 0 \\
$\operatorname{mdx} 5$ & 0 & 0 & 0 & 1,1 & $1,1,1$ & 1 \\
& 0 & 0 & 0 & 1,1 & $1,1,1,1$ & 1,1 \\
& 0 & 0 & 0 & $1,3,3$ & 1 & 1 \\
& 0 & 0 & 0 & 1 & 1 & 1,2 \\
\hline
\end{tabular}

* The results are presented from three different sections, which contained the greatest number of revertants of the 10 sections examined. Each number represents the number of cells in each cluster of revertants. Each row is from a different animal.
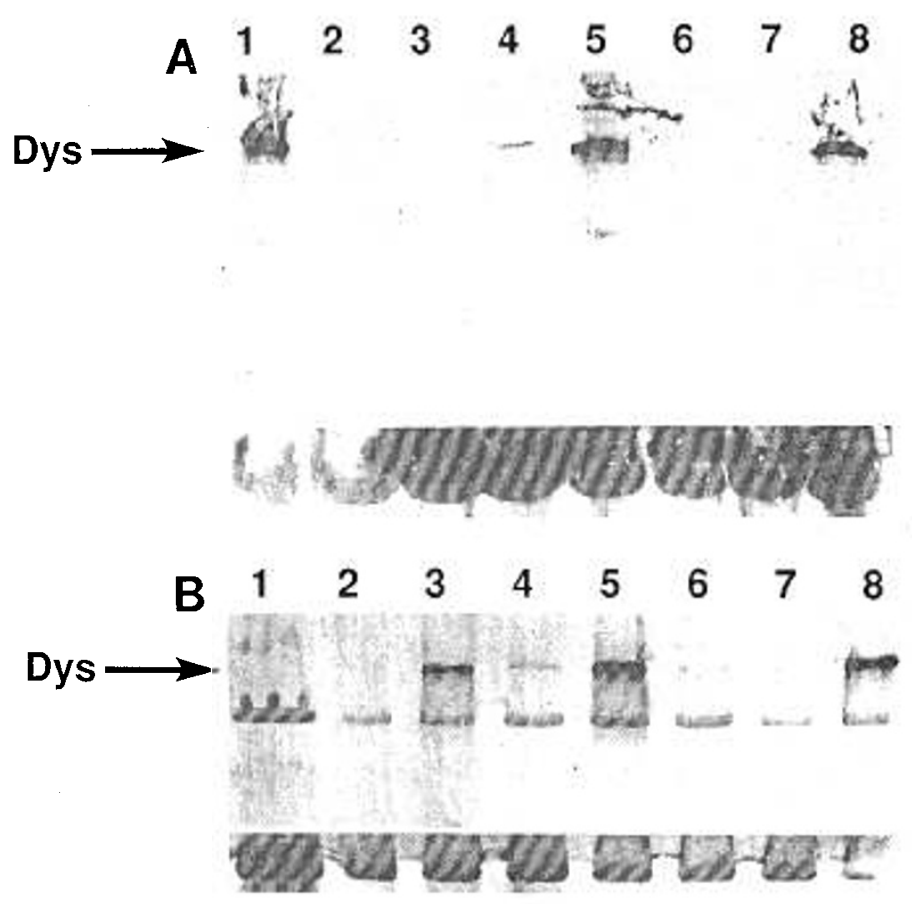

Fig. 3. Immunoblot analysis using the 6-10 antibody of quadriceps $(A)$ and cardiac $(B)$ muscles from the various mouse strains. Lower panels represent the myosin on the blots stained with india ink. Arrows indicate location of dystrophin. $A$, Lanes 1,5 , and 8 , normal BALB/c; lane $2, \mathrm{mdx} 5$ mutant; lane $3, \mathrm{mdx} 4$ mutant; lane $4, \operatorname{mdx} 3$ mutant; lane 6 , mdx2 mutant; and lane $7, \mathrm{mdx} . B$, Lane $1, \operatorname{mdx} 5$ mutant; lane 2, mdx 4 mutant; lanes 3, 5, and 8 , normal BALB/c; lane 4, mdx3 mutant; lane $6, \mathrm{mdx} 2$ mutant; and lane $7, \mathrm{mdx}$.

for each of the mutants (Fig. $3 B$ ). Dystrophin was never observed in the $\mathrm{mdx} 4$ or $\operatorname{mdx} 5$ mutants (Fig. $3 B$, lanes 1 and 2 ), but low and variable amounts were observed in half of the 10 immunoblots performed on the extracts of $\mathrm{mdx} 2$ or $\mathrm{mdx}$ hearts (Fig. $3 B$, lanes 6 and 7). This variable and very faint dystrophin staining may have been observed only in this study to date because of the use of the sensitive 6-10 antibody. If it was due to expression of the X-chromosomal dystrophin or a dystrophin-related protein, it is not clear why it was only observed in the heart extracts.

In 10 immunoblots from five hearts of $\mathrm{mdx} 3$ mice, faint dystrophin staining was consistently observed to be greater than that in the $\mathrm{mdx}$ or $\mathrm{mdx} 2$ mice (Fig. $3 B$, lane 4 ).

\section{DISCUSSION}

The number of revertants in skeletal and cardiac muscle differed significantly among the $\operatorname{mdx}, \operatorname{mdx} 2, \operatorname{mdx} 3, \operatorname{mdx} 4$, and $\mathrm{mdx} 5$ mutants. The mdx and $\mathrm{mdx} 2$ mutants both had the largest number of revertants with approximately 20 to 30 revertants per quadriceps cross-section at 2 mo of age, and approximately 200 revertants per quadriceps cross-section at 6 mo of age. The mdx 4 and $\mathrm{mdx} 5$ mutants had approximately 10 -fold fewer mutants than the mdx and mdx 2 mutants at both 2 and 6 mo of age, with less than five revertants per quadriceps cross-section at 2 mo and less than 20 at 6 mo. The number of cardiac revertants was also greater in the $\mathrm{mdx}$ and $\mathrm{mdx} 2$ mutants than in the $\mathrm{mdx} 5$ or mdx 3 mutants.

In the previous study, the number of revertants in mdx mice varied by at least 10 -fold between the mdx mice maintained in the London and Boston laboratories (9). Different genetic backgrounds of the Boston and London mdx mice may have been the cause of their different reversion rates. Because the mdx2, $\mathrm{mdx} 4$, and $\mathrm{mdx} 5$ mice were bred to congenicity onto the C57BL/ 6Ros background for more than 10 generations, it is highly unlikely that their different reversion rates were due to different 
genetic backgrounds. Viral infections may have also caused the disparity in revertant frequency between the mdx mice bred at the London and Boston laboratories. In this study, similar revertant frequencies were observed in the mice bred in either the Buffalo or Madison laboratory. Because the mutants were housed in the same room and analyzed in one laboratory, it is unlikely that the different reversion rates among the mutants were due to differences in viral infections or laboratory procedures. More likely, the reversion rates are different because of differences in the location or type of the point mutation in the various mutants. To further explore the basis for the different reversion rates among the mutants, mdx mice have been bred with $\mathrm{mdx} 5$ mice to generate female heterozygotes. The differences in reversion rates among the mutants has potential implications concerning the mechanism and nature of the revertants.

The relatively larger number of revertants in the mdx mutants has complicated the analyses of gene or cell therapies. The high background increases the difficulty in assessing the efficacy of the new therapies based on the ability of the experimental therapy to increase the number of dystrophin-positive fibers. The few revertants in the mdx 4 and $\mathrm{mdx} 5$ mutants indicates that these mutants will be useful for the evaluation of gene and cell therapy approaches in mice. The pathology in the quadriceps, cardiac, and diaphragm muscles of the $\mathrm{mdx} 4$ and $\mathrm{mdx} 5$ mutants indicates that they will be as useful as the original $\mathrm{mdx}$ mouse in this regard.

The faint dystrophin immunofluorescence at the skeletal sarcolemma in the mdx 3 mutants is of interest. None of the other mutants had such faint sarcolemmal immunofluorescence. On immunoblot analysis, the skeletal muscle of the $\mathrm{mdx} 3$ mutants also had small amounts of dystrophin, whereas the $m d x, m d x 2$, $\mathrm{mdx} 4$, and $\mathrm{mdx} 5$ mutants did not. The low dystrophin levels in the mdx 3 mutants were not able to prevent the pathology of the skeletal or diaphragm muscles. Human DMD patients with similar low levels of dystrophin have been described, and the mdx 3 mutant will be useful as a model for this class of dystrophic patients $(19,20)$.

The hearts of the mdx 3 mutants consistently had low levels of dystrophin on immunoblots, but their cardiac sarcolemma did not have dystrophin immunofluorescence. The sarcolemmal location of a mutated dystrophin in skeletal but not cardiac muscle has not been noted in humans previously, and its molecular basis is speculative. The $\operatorname{mdx} 3$ mutated dystrophin protein may be able to complex with dystrophin-associated proteins in skeletal muscle, but not in cardiac muscle (2), or perhaps the mdx3 dystrophin mRNA is spliced differently in cardiac and skeletal muscle (21).

Acknowledgments. The authors thank E. Langer for technical assistance, T. Byers and L. Kunkel for the 6-10 antibody. Eric Hoffman for antibodies $1-2 \mathrm{a}, 30-\mathrm{kD}$, and d10, and J. Fritz for help with the immunoblots.

\section{REFERENCES}

1. Sicinski P, Geng Y, Ryder-Cook AS, Barnard EA, Darlison MG, Barnard PJ 1989 The molecular basis of muscular dystrophy in the mdx mouse: a point mutation. Science 244:1578-1580

2. Ervasti JM, Ohlendieck K, Kahl SD, Gaver MG, Campbell KP 1990 Deficiency of a glycoprotein component of the dystrophin complex in dystrophic muscle. Nature 345:315-319

3. Lucas-Heron B, Mussini JM, Ollivier B 1989 Is there a maturation defect related to calcium in muscle mitochondria from dystrophic mice and Duchenne and Becker muscular dystrophy patients? J Neurol Sci 90:299-306

4. Fong P, Turner PR, Denetclaw WF, Steinhardt RA 1990 Increased activity of calcium leak channels in myotubes of Duchenne human and mdx mouse origin. Science 250:673-676

5. Franco A, Lansman JB 1990 Calcium entry through stretch-inactivated ion channels in mdx myotubes. Nature 344:670-673

6. Hoffman EP, Gorospe RM 1991 The animal models of Duchenne muscular dystrophy: windows on the pathophysiological consequences of dystrophin deficiency. In: Mooseker MS, Morrow JS (eds) Current Topics in Membranes. Academic Press, Inc, San Diego, CA, pp 113-154

7. Stedman HH, Sweeney HL, Shrager JB, Maguire HC, Panettieri RA, Petrof B, Narusawa M, Leferovich JM, Sladky JT, Kelly AM 1991 The mdx diaphragm reproduces the degenerative changes of Duchenne muscular dystrophy. Nature 352:536-539

8. Chapman VM, Miller DR, Armstrong D, Caskey CT 1989 Recovery of induced mutations for X-chromosome-linked muscular dystrophy in mice. Proc Natl Acad Sci USA 86:1292-1296

9. Hoffman EP, Morgan JE, Watkins SC, Slayter HS, Partridge TA 1990 Somatic reversion/suppression of the mouse $\mathrm{mdx}$ phenotype in vivo. J Neurol Sci 99:119-125

10. Ohlendieck K, Ervasti JM, Matsumura K, Kahl SD, Leveille CJ, Campbell KP 1991 Dystrophin-related protein is localized to neuromuscular junctions of adult skeletal muscle. Neuron 7:499-508

11. Love DR, Morris GE, Ellis JM, Fairbrother U, Marsden RF, Bloomfield JF, Edwards YH, Slater CP, Parry DJ, Davies KE 1991 Tissue distribution of the dystrophin-related gene product and expression in the $\mathrm{mdx}$ and dy mouse. Proc Natl Acad Sci USA 88:3243-3247

12. Partridge TA, Morgan JE, Coulton GR, Hoffman EP, Kunkel LM 1989 Conversion of $\mathrm{mdx}$ myofibers from dystrophin-negative to dystrohine-positive by injection of normal myoblasts. Nature 337:176-179

13. Acsadi G, Dickson G, Love DR, Jani A, Walsh FS, Gurusinghe A, Wolff J, Davies KE 1991 Human dystrophin expression in mdx mice after intramuscular injection of DNA constructs. Nature 352:815-818

14. Lidov HGW, Byers TJ, Watkins SC, Kunkel LM 1990 Localisation of dystrophin to postsynaptic regions of central nervous system cortical neurons. Nature 348:725-728

15. Koenig M, Kunkel LM 1990 Detailed analysis of the repeat domain of dystrophin reveals 4 potential hinge regions that may confer flexibility. J Biol Chem 265:4560-4566

16. Hoffman EP, Brown RA, Kunkel LM 1987 Dystrophin: the protein product of the Duchenne muscular dystrophy locus. Cell 51:919-928

17. Hoffman EP, Beggs AH, Koenig M, Kunkel LM, Angelini C 1989 Crossreactive protein in Duchenne muscle. Lancet 2:1211-1212

18. Dubowitz W, Brooke MH 1973 Muscle Biopsy. A Modern Approach. WB Saunders, London

19. Beggs AH, Hoffman EP, Snyder JR, Arahata K, Specht L, Shapiro F, Angelini C, Sugita H, Kunkel LM 1991 Exploring the molecular basis for variability among patients with Becker muscular dystrophy: dystrophin gene and protein studies. Am J Hum Genet 49:54-67

20. Hoffman EP, Fishbeck KH, Brown RH, Johnson M, Medori R, Loike JD Harris JB, Waterston R, Brooke M, Specht L, Kupsky W, Chamberlain J, Caskey CT, Shapiro F, Kunkel LM 1988 Characterization of dystrophin in muscle biopsy specimens from patients with Duchenne's or Becker's muscular dystrophy. N Engl J Med 318:1363-1368

21. Feener CA, Koenig M, Kunkel LM 1989 Alternative splicing of human dystrophin mRNA generates isoforms at the carboxy terminus. Nature 338:509-511 